\title{
WHAT DOES IT MEAN “TO BE A GOOD NURSE”? PERCEPTIONS OF NURSING STUDENTS
}

\author{
Vilma Zydziunaite \\ Vytautas Magnus University, Klaipeda State University of Applied Sciences, \\ Lithuania St. Loyola of Ignatius University of Applied Sciences, Lithuania
}

\section{Ramune Bagdonaite-Stelmokiene}

Vytautas Magnus University, Lithuania

\begin{abstract}
To be a good nurse" is a complex phenomenon. It is the essential goal in nursing training, education and practice, and can be experienced through work practice. However, "to be a good nurse" is taken for granted and is rarely studied, mostly with the focus on personal features and in relation to good nursing and quality of nursing. The aim was to reveal nursing students' work experience-based perceptions of the personal meaning of "to be a good nurse". Sample. Research participants comprised 110 final year nursing students. Methods. For data collection were used unstructured individual narrative-based written reflections and the data was analyzed by applying the inductive manifest qualitative content analysis. Results. For nursing students "to be a good nurse" means courage, professionalism, loyalty, humanity, solidarity and caring. It is an individually experienced phenomenon, meaningful for nursing students when they collaborate with nurse practitioners, learn through cooperation and observation, and have the opportunity to act autonomously by taking responsibility for their own actions. Conclusion. "To be a good nurse" is a part of who the student is and the values that s/he holds dear to her/him.
\end{abstract}

Keywords: good nurse, inductive manifest qualitative content analysis, Lithuania, nursing student, reflection.

\section{Introduction}

"To be a good nurse" requires more than professional values of care and compassion (De Carvalho Macedo, 2014). Beyond this the nursing student can decide what kind of a nurse s/he wishes to be. A good nurse would want to make a difference and must be a knowledgeable, competent, skillful critical thinker and sympathetic personality (Ghadirian, Salsali, \& Cheraghi, 2014).

"To be a good nurse" in this research is understood as a phenomenon in which the notion "to be" is essential, and is not the same as "being" or "to become". Here "to be" means exists, happens, is located and shows identity; the condition of the subject (Free English Grammar Guide, 2017). The condition of the subject - a nursing student - in this research is seen as personal and professional development, change, transformation in striving "to be a good 
Zydziunaite \& Bagdonaite-Stelmokiene, 2020. What Does it Mean "to be a Good Nurse"?

Perceptions of Nursing Students

nurse”, and this is possible through learning from nurse practitioners at all times of study practice in healthcare institutions.

"To be", in this research is not a synonym for "becoming", which means "begin to be" (Thesaurus.com, 2017). "Becoming" is focused on the process, and the individual here must be the instrument in the process, hence the priority is the process itself. This is different from "to be", where the process also has a place, but the individual with her/his features and competencies is the "outcome", which is never the status quo, and is oriented toward the best examples of role models (Hawkins \& Morse, 2014).

Perceptions of nursing students in this research are seen as a complex mental process of acquiring knowledge and understanding through thought, experience, and the senses. Our knowledge and experience influence the way we perceive the world (Khademian \& Vizeshfar, 2008).

No primary research studies in Lithuania were found in regard to the phenomenon "to be a good nurse". Internationally, research focuses on a nurse's personal features such as being caring, intelligent, calm, positive, communicative, respectful, self-confident, skillful, mindful (Kleber, 2015), motivating others, cooperative, loving, contributing to others' health (Sua, 2013), compassionate, empathetic, selfless, self-aware, technically strong with a thirst of knowledge (Gokenbach, 2012). "To be a good nurse" in the literature is described within the context of "a great nurse” (Middleton, 2014), "nurse’s behaviour” (Larsson, Sahlsten, Segesten, \& Plos, 2011), “good care” (Mako, Svanäng, \& Bjerså, 2016), "individualised care" (Suhonen, Välimäki, \& Leino-Kilpi, 2002) from the perspective of nurses, patients or their relatives. No attention is paid to students' perspectives in regard to the phenomenon of "to be a good nurse".

The aim of this study was to reveal and describe nursing students' work experience-based perceptions with regard to the meaning of "to be a good nurse". This qualitative research was focused on answering this research question: "What does ‘to be a good nurse' mean for final study year nursing students?”

\section{Methodology}

\section{Sampling and Data Collection}

This study applied purposive sampling. There are no methodological tradition established criteria when using inductive manifested qualitative content analysis (IMQCA), for the number of informants, nor the number of pages based on the informants' written text (Bengtsson, 2016). Two criteria for respondents' search were chosen: i) being a final (3rd) year and a final (6th) semester nursing student at professional Bachelor level; ii) being a student of the University of Applied Sciences (UAS). The sample consisted of 110 research participants from all 5 UAS in all 5 regions of Lithuania. 
Data were collected in the format of unstructured individual narrative-based written reflections (INWR). The experience-based reflections are necessary for nursing students to improve their practice(s) and must be used for their professional growth (Castleberry, Payakachat, Ashby, Nolen, Carle, Neill, \& Franks, 2016). The data collection with INWR was a onetime event and research participants were not re-contacted. Nursing students were instructed to narrate the situation regarding their experiences during professional nursing practice in healthcare institutions throughout their study years when they had experienced "what does it mean to be a good nurse" by observing nurse practitioners and collaborating with them. The length of written reflections was between 301 and 1,027 words. In total, the analyzed text consisted of 52,675 words.

\section{Data Analysis}

Research using IMQCA focuses on the characteristics of language as communication with attention to the content and contextual meaning of the text (Elo \& Kyngäs, 2008). In IMQCA, data are presented through (sub)categories. IMQCA consists of four stages (Bengtsson, 2016): i) The decontextualization. The research team applied the multiple reading of the transcribed texts to obtain the sense of the whole, before breaking it down into smaller meaningful analysis units (MAU). The MAU was at least one sentence and each identified MAU was labelled with a code. ii) The recontextualization. The research team checked whether all aspects of the MAU content had been covered in relation to the research question. The original text was re-read alongside the final list of MAUs. iii) The categorization. All the subcategories were compared with each other and integrated into categories. Categories were internally homogenous and externally heterogeneous, which means that not data should fall between two groups and not fit into more than one group. iv) The compilation. The research team worked through each category and used the research participants' words, remaining aware of the need to refer back to the original text. For each category, the researchers chose appropriate MAU presented in the running text as quotations.

\section{Ethics}

Ethical approval for research study was received from the Board of Ethics of the Vytautas Magnus University (24.06.2017, Protocol No. 5). Written permission to carry out the investigation was granted by Vice-Directors for Studies and Research of all five Universities of Applied Sciences (UAS), in which nursing students are trained and educated. All nursing students from the five UAS were sent an e-mail with information about the research purpose and what the research required of them. After nursing students received information about the research, they voluntarily made the decision whether to participate in the study, and e-mailed their agreement to the researcher (RB-S). Then they received by email a request from the researcher (RB-S) to write the INWR. All the INWR of research participants were received by e-mail by one researcher (RB-S) and 
Zydziunaite \& Bagdonaite-Stelmokiene, 2020. What Does it Mean “to be a Good Nurse”? Perceptions of Nursing Students

collected in one file accessible only to the research team. Research participants were asked not to provide their names, surnames or other personal confidential information.

\section{Findings}

Final study year nursing students relate their experiences of work practices throughout their study years and speak about the personal meaning in regard to the phenomenon "to be a good nurse". By observing nurse practitioners, reflecting on practical experiences and compiling the nurse practitioners work patterns or models, nursing students remember facts and illustrate them with examples, whose analysis revealed that "to be a good nurse" for nursing students means courage, professionalism, loyalty, humanity, solidarity and caring (see Table 1).

Table 1 What does it mean "to be a good nurse": graduating nursing students' perspective

\begin{tabular}{|l|l|}
\hline \multicolumn{1}{|c|}{ Category } & Subcategory \\
\hline \multirow{5}{*}{ Courage } & Being self-confident \\
\cline { 2 - 3 } & Being tolerant \\
\cline { 2 - 3 } & Being prompt \\
\cline { 2 - 3 } & Stabilizing the patient's emotions \\
\hline \multirow{5}{*}{ Professionalism } & Being responsible \\
\cline { 2 - 3 } & Being in compliance with requirements and rules \\
\cline { 2 - 3 } & Being accurate \\
\cline { 2 - 3 } & Managing the personal emotions \\
\cline { 2 - 3 } & Being autonomous in planning and implementing activities \\
\hline \multirow{5}{*}{ Humanity } & Being dedicated to work \\
\cline { 2 - 3 } & Experiencing vocation \\
\cline { 2 - 3 } & Being dutiful \\
\hline & Being patience \\
\hline & Being benevolent (good will) \\
\hline & Being sensitive \\
\cline { 2 - 3 } & Being empathetic \\
\hline & Being friendly \\
\hline
\end{tabular}


Proceedings of the International Scientific Conference. Volume II, May $22^{\text {th }}-23^{\text {th }}, 2020.503-512$

\begin{tabular}{|l|l|}
\hline \multirow{4}{*}{ Solidarity } & Being polite \\
\cline { 2 - 2 } & Being intelligent \\
\hline \multirow{5}{*}{ Caring } & Experiencing unity \\
\cline { 2 - 2 } & Reacting fast \\
\hline & Assuring (securing) the patient's dignity \\
\hline & Being supportive \\
\hline & Establishing the relationship \\
\hline & Informing patient's relatives \\
\cline { 2 - 3 } & Teaching patient's relatives \\
\hline & Empowering the patient for self-care \\
\hline
\end{tabular}

Courage is reflected through the personality of a nurse, who maintains a professional relationship with the patient, who manages personal and patient's emotions, makes decisions on time and is self-confident:

One nurse who has been working on this job for many years did not agree with the prescription of a doctor because she thought the dose was too high. $<\ldots>$ the nurse concerned with the prescribed dose giving rise to suspicion, went to a doctor and found that he was still wrong (N7).

In all nurses' professional activities and decisions nursing students relate to the patient for whose health and life s/he is working. Irrespective of the patient's emotions, the good nurse is tolerant: "it was possible to see that the nurse was able to communicate with patients; she tolerated all patients' insults” (N23).

The good nurse should be with a timely response to the situation and stabilizing the patient's emotions:

He was very insolent - he spat, cried, sighed - he was probably drunk. In spite of these circumstances, the nurse, without hesitation, entered the patient's room. I, observing from afar, saw how a nurse communicates gently and with respect for the patient, as the patient caught his breath in a matter of minutes, and became calm (N88).

Professionalism for nursing students means professionalism, which they relate to her/his responsibility and accuracy:

In the morning the young patient - a woman - was moved into the stroke department $<\ldots>>$ she was in a very bad condition. I saw how nurses cared about her the all the time she was in the department. Nurses were ultimately responsible for any injections (N30).

When she came to work, she immediately monitored the nursing plans left by other nurses by checking the record of injections and other procedures. When 
Zydziunaite \& Bagdonaite-Stelmokiene, 2020. What Does it Mean "to be a Good Nurse"? Perceptions of Nursing Students

the nurse did her job, she crafted everything very carefully $<\ldots>$ she loved the order very much (N56).

Students relate professionalism to compliance with requirements and rules, autonomy in planning and implementing activities: "A nurse, who graduated in nursing long time ago, she still performs all the procedures according to all requirements” (N72).

Loyalty is manifested in two directions -

Nursing profession, this is expressed through dedication to work and vocation:

One of the values I could highlight is dedication to work. During the practice, many times, I have had to face wonderful nurses who love their job endlessly, but they love the patient the most by striving to help him/her with all the professional strength (N55).

Personal features of the nurse - dutifulness, which is related to the quality of caring and to the example of the ideal professional role model for nurse students: "the nurse is very dutiful. You always thought that she had to finish the job first, before she could rest. Such a dedicated nurse is a great example not only for me but for every student nurse" (N56); and patience, which is oriented to the relationship with the patient: "an elderly patient, who was very angry and unhappy with everything, was placed in the ward. So I was very impressed by the nurse's patience” (N23).

Humanity is empowered through a nurse's direct relationship with the patient and is based on the nurse's good will and sensitivity:

My most memorable event was when I observed the nurse communicating with an elderly woman. The nurse listened sincerely to what the woman patient said and also willingly answered the questions the patient had; the nurse attentively communicated with the patient as if she were a member of her family (N12).

And empathy, friendliness, politeness, and intelligence:

After this event, I remembered words of the chief nurse that a nurse is a person who has to understand that the patient, while sleeping in a hospital, in a foreign environment, feels emotional, and the nurse must be intelligent (N55).

Solidarity is related to a focus on the patient's health and life which requires an important unity:

A woman with a poli-trauma was brought into the ward and she was in need of emergency assistance. Then the teamwork started: I connected the patient to the monitor; others intubated the patient, inserted a bladder catheter, and took blood samples. So I figured out how to work in a team (N24).

Also it requires fast reaction:

There was a calm response by the nurses. It seems everyone knew what to do and what they are responsible for. One called for reanimation, another was taking measurements and collected instruments/tools, and a third went to look for physicians (N47). 
Caring is implemented by the nurse with the focus on two subjects:

1) the patient through ensuring his/her dignity: "when the patient has drowned and the nurse has taken care of moving other patients to another ward, to ensure the privacy of the dying patient" (N54); establishing the mutual trustbased relationship:

The nurse was able to properly access the patient, knowing what to ask, and gradually established a connection between her and the patient. Finally, the girl began to communicate more and more with the staff and with her loved ones (N44);

Ensuring patient's empowerment for self-care: “And the general purpose of all is not to do everything for that person, but to teach him/her to take care of him/herself” (N81).

2) patient's relatives by providing them with moral and psychological support:

After the patient was transferred, the nurse, who noticed a crying and the "lost" relative of the patient, did not ignore her and did not return immediately to the unit, but came to the patient's relative, took her by the arm, led her to sit down and tried to soothe her (N85).

Informing them about the situation and helping to plan and strategize help to the patient at home and teaching them the subtleties of patient care at home: "taught the family members how to properly help to change the patient's position in bed, how to properly maintain patient hygiene” (N11).

\section{Discussion}

Nursing students find the meaning of the phenomenon of "to be a good nurse" in relation to courage, which in findings is manifested within the interactions between the nurse and the patient, where the nurse acts for the patient's wellness. The nurse requires professional courage to maintain the personal ability to engage the self in care (Arman, 2007) and to help patients face their own vulnerability and suffering (Thorup, Rundqvist, Roberts, \& Delmar, 2012).

"To be a good nurse" for nursing students means professionalism, which is related autonomy in planning and implementing activities. Nurses as professionals are independent decision-makers in healthcare provision (Ghadirian et al., 2014). Nursing students emphasise that accuracy for them is a part of a nurse's professionalism. Maintaining standards of activities is important in nursing professionalism, and for a nurse it means being precise and accurate (Jonsen, Braddock, \& Edwards, 2016).

Nursing students mention that loyalty means a nurse's features such as patience and dutifulness, when both features are incorporated within the nurse's 
Zydziunaite \& Bagdonaite-Stelmokiene, 2020. What Does it Mean "to be a Good Nurse"?

Perceptions of Nursing Students

patient relationship. This "relational loyalty" (Moody \& Pesut, 2006) develops from fostering mutual trust between the nurse and the patient.

Nursing students emphasise the nurse-patient relationship as the context and the aim through which the nurse may express her/his humanity. Once the nurse sees patients as an extension of her/his own humanity, s/he will go that extra mile to do the best s/he can for them (Felstead \& Springett, 2016).

Nursing students mention that the focus of nurses' solidarity is on patients' health and life. Solidarity includes the responsibility of nurses to prevent outbreaks of illness when working in institutions where vulnerable human beings live and suffer (Dawson \& Verweij, 2012).

For nursing students caring ensures the patient's dignity, establishing mutual trust and empowering the patient's self-care. It follows that a good nurse who really 'cares' wants evidence about how to achieve the outcomes, and needs the skills to make decisions in complex situations (Sherman, 2012).

Study limitations. The limitation of the study relates to IMQCA, which is inherently reductive, disregarding the context that produced the text, as well as the state of things after the text is produced.

\section{Conclusion}

"To be a good nurse" is a personal and professional development and improvement-based phenomenon, which is meaningful for nursing students when they have the opportunity to collaborate with nurse practitioners and to learn through cooperation, observation and autonomous practice. This phenomenon is process-related, which motivates nursing students to reflect before, in and after professional acting/ practicing. It means seeking to be the best role model, which is realistic, based on work practice.

"To be a good nurse" for nursing students means a great opportunity for everyday interaction with patients, their relatives, colleague nurses, healthcare/medical staff and administrators. This gives the nurse the possibility to learn from other careers and add to her/his knowledge base while developing one's own interpersonal skills. "To be a good nurse" for nursing students is a part of who the students are and the values that they hold dear - integrity, lifelong learning, excellence, proficiency and connection.

\section{References}

Arman, M. (2007). Bearing Qitness: an Existential Position in Caring. Contemporary Nurse, 27(1), 84-93. doi: 10.5555/conu.2007.27.1.84

Bengtsson, M. (2016). How to Plan and to Perform the Qualitative Study Using Content Analysis. NursingPlus Open, 2, 8-14. Retrieved from http://www.sciencedirect.com/ science/article/pii/S2352900816000029 
Castleberry, A. N., Payakachat, N., Ashby, S., Nolen, A., Carle, M., Neill, K. K., \& Franks, A. M. (2016). Qualitative Analysis of Written Reflections During a Teaching Certificate Program. American Journal of Pharmaceutical Education, 80(1), 10. doi: 10.5688/ajpe80110

Dawson, A., \& Verweij, M. (2012). Solidarity: a Moral Concept in Need of Clarification. Public Health Ethics, 5(1), 1-5. doi: https://doi.org/10.1093/phe/phs007

De Carvalho Macedo, A. P. (2014). Nursing Supervision: Studying the "Case" of the Phenomenon of Interorganizational Articulation Nursing School and Hospital. Revista da Escola de Enfermagem da USP, REEUSP, 48(2), 190-196. doi: 10.1590/S0080623420140000800028

Elo, S., \& Kyngäs, H. (2008). The Qualitative Content Analysis Process. Journal of Advanced Nursing, 62(1), 107-115. doi: 10.1111/j.1365-2648.2007.04569.x

Felstead, I. S., \& Springett, K. (2016). An Exploration of Role Model Influence on Adult Nursing Students' Professional Development: a Phenomenological Research Study. Nurse Education Today, 37, 66-70. doi: 10.1016/j.nedt.2015.11.01

Free English Grammar Guide. (2017). The Verb To Be. [cited 2017 Apr 17]. Retrieved from https://sites.google.com/site/englishgrammarguide/Home/the-verb-to-be

Ghadirian, F., Salsali, M., \& Cheraghi, M. A. (2014). Nursing Professionalism: an Evolutionary Concept Analysis. Iranian Journal of Nursing and Midwifery Research, 19(1), 1-10. Retrieved from https://www.ncbi.nlm.nih.gov/pmc/articles/PMC3917177/

Gokenbach, V. (2012). 5 Things That Make a Good Nurse Great. Nurse Together. Retrieved from http://www.nursetogether.com/5-things-that-make-a-good-nurse-great

Hawkins, S. F., \& Morse, J. (2014). The Praxis of Courage as a Foundation for Care. Journal of Nursing Scholarship, 46(4), 263-270. doi: 10.1111/jnu.12077

Jonsen, A. R., Braddock, C. H., \& Edwards, K. A. (2016). Professionalism. Ethics in Medicine. University of Washington School of Medicine. Retrieved from https://depts.washington. edu/bioethx/topics/profes.html

Khademian, Z., \& Vizeshfar, F. (2008). Nursing Students' Perceptions of the Importance of Caring Behaviors. Journal of Advanced Nursing, 61(4), 456-462. doi: 10.1111/j.13652648.2007.04509.x

Kleber, K. (2015). What Does It Mean To Be “a Good Nurse”? SCRUBS: The Nurse's Guide to Good Living. Retrieved from http://scrubsmag.com/what-does-it-mean-to-be-a-goodnurse/

Larsson, I. E., Sahlsten, M. J. M., Segesten, K., \& Plos, K. A. E. (2011). Patients’ Perceptions of Nurses' Behaviour That Influence Patient Participation in Nursing Care: a Critical Incident Study. Nursing Research and Practice, Article ID 534060, 8 pages. doi: 10.1155/2011/534060

Mako, T., Svanäng, P., \& Bjerså, K. (2016). Patients’ Perceptions of the Meaning of Good Care in Surgical Care: a Grounded Theory Study. BMC Nursing, 15, 47. doi: 10.1186/s12912016-0168-0

Middleton, J. (2014). Taking a Patient Perspective. Nursing Times. 30 January 2014. Retrieved from https://www.nursingtimes.net/break-time/role-models/taking-a-patient-perspective/ 5067432.article

Moody, R. C., \& Pesut, D. J. (2006). The Motivation to Care: Application and Extension of Motivation Theory to Professional Nursing Work. Journal of Health Organization and Management, 20(1), 15-48. doi: https://doi.org/10.1108/14777260610656543

Sherman, R. O. (2012). An Attitude of Gratitude. Retrieved from http://www.emergingrnleader.com/gratitudeandnursingleadership/ 
Zydziunaite \& Bagdonaite-Stelmokiene, 2020. What Does it Mean "to be a Good Nurse”?

Perceptions of Nursing Students

Sua, Ch. (2013). “Every Past Interaction I Have Had With Nurses Has Inspired Me”. Marian University: Accelerated Nursing Programmes. Retrieved from http://onlineabsn.marian. edu/blog/every-past-interaction-i-have-had-with-nurses-has-inspired-me/

Suhonen, R., Välimäki, M., \& Leino-Kilpi, H. (2002). “Individualised Care” From Patients', Nurses' and Relatives' Perspective - a Review of the Literature. International Journal of Nursing Studies, 39(6), 645-654. doi: http://dx.doi.org/10.1016/S0020-7489(02)00004-4 Thesaurus.com (2017). Retrieved from http://www.thesaurus.com/browse/become

Thorup, Ch. B., Rundqvist, E., Roberts, Ch., \& Delmar, Ch. (2012). Care as a Matter of Courage: Vulnerability, Suffering and Ethical Formation in Nursing Care. Scandinavian Journal of Caring Sciences, 26(3), 427-435. doi: 10.1111/j.1471-6712.2011.00944.x 